\title{
ASPECTOS BIOLÓGICOS DE Campoletis flavicincta (ASHMEAD) (HYMENOPTERA: ICHNEUMONIDAE) E INTERAÇÕES COM O VÍRUS DA POLIEDROSE NUCLEAR DE Spodoptera frugiperda
}

\author{
WALTER JOSÉ RODRIGUES MATRANGOLO ${ }^{1}$, ANGÉLICA MARIA PENTADO MARTINS-DIAS² \\ e IVAN CRUZ ${ }^{1}$
}

1. Embrapa Milho e Sorgo. MG 424, Km 65. Sete Lagoas, MG, Caixa Postal 151. CEP 35701970.

${ }^{2}$ Universidade Federal de São Carlos, SP. Programa de Pós-Graduação em Ecologia e Recursos Naturais (PPGERN). Rod. Washington Luís, Km 235. São Carlos, SP. Caixa Postal 676. CEP 13565-905.

Revista Brasileira de Milho e Sorgo, v.6, n.1, p.1-16, 2007

\begin{abstract}
RESUMO - O Vírus da Poliedrose Nuclear de Spodoptera frugiperda (VPN - Sf) e o parasitóide Campoletis flavicincta competem pelo mesmo recurso: lagartas de $S$. frugiperda nos estádios iniciais. Foram estudados alguns aspectos biológicos do parasitóide e avaliada a sua capacidade de diferenciar lagartas sadias e infectadas. Mais de um ovo do parasitóide foi encontrado dentro da maioria das lagartas de $S$. frugiperda. O período de incubação dos ovos de $C$. flavicincta foi de aproximadamente 48 horas. Cerca de 24 horas após a eclosão das larvas do parasitóide, foi possível notar que apenas uma das larvas cresceu. Provavelmente, na competição intra-específica, a eliminação das larvas concorrentes do parasitóide dentro de uma mesma lagarta aconteça pelo ataque físico, dada à morfologia das larvas de primeiro estádio (presença de mandíbulas, que inexistem nos estádios posteriores). No tratamento sem opção de escolha, mais ovos foram depositados em lagartas sadias. No teste em olfatômetro, a presença de lagartas de S. frugiperda (infectadas ou não) determinou a maior atração de fêmeas. A existência de discriminação entre lagartas sadias e infectadas pode minimizar o impacto negativo do vírus sobre o parasitóide. Os dados relativos às interações desses dois organismos, que mantêm relações estreitas entre si, devem nortear as decisões que garantam uma maior biodiversidade no agroecossistema do milho.
\end{abstract}

Palavras-chave: competição intra-específica, atratividade, discriminação de hospedeiro, impacto.

\section{BIOLOGICAL ASPECTS OF Campoletis flavicincta (ASHMEAD) (HYMENOPTERA: ICHNEUMONIDAE) E INTERACTIONS WITH THE VIRUS OF THE NUCLEAR POLIEDROSE OF Spodoptera frugiperda}

\begin{abstract}
The Nuclear Polyhedrosis Virus of S. frugiperda (J. E. Smith) (Lepidoptera: Noctuidae) (NPV - Sf) and the parasitoid Campoletis flavicincta (Ashmead) (Hymenoptera: Ichneumonidae) compete for the same resource, that is, firsts instars of S. frugiperda. Biological aspects and the capacity of the parasitoid to differentiate between healthy hosts larvae and infected by NPV - $S f$ were studied under laboratory conditions. More than one egg of parasitoid was found inside of the majority of $S$. frugiperda larvae. Incubation period was approximately 48 hours. Only one developed larvae could be
\end{abstract}


observed 24 hours after the parasitoid hatching. Probably, due to intra specific competition by physical attack among first stadium larvae (presence of jaws, that does not exist at the subsequent stadiums), only one survived. In the treatment without choice option, more eggs had been deposited in healthy larvae. In the olfactometer test, the presence of $S$. frugiperda larvae (infected or not) determined the greater attraction of females. The female parasitoid discrimination between healthy and infected host larvae can minimize the negative impact of the virus on the parasitoid. The data related to the interactions of those two organisms that maintain close relationships to each other, should direct the decisions that guarantee a larger biodiversity in the agro ecosystem of the corn crop.

Key words: intra specific competition, attractive, host discrimination, impact.

A lagarta-do-cartucho Spodoptera frugiperda (J. E. Smith) (Lepidoptera: Noctuidae) impõe grandes perdas à produção de milho (Zea mays L.) não só no Brasil, mas em toda a América (Cruz \& Turpin, 1983, Cruz et al., 1997a, 1999, Figueiredo et al., 2006).

O controle dessa praga ainda tem sido realizado com inseticidas químicos, geralmente, de baixa seletividade, afetando negativamente os agentes de controle biológico natural e poluindo o meio ambiente (Cruz, 1995).

A redução do uso de agrotóxicos nas práticas agrícolas é desejável e possível com o subsídio da biodiversidade natural, que, cada vez mais, colabora para uma produção mais equilibrada ecologicamente. Com um manejo adequado, os agentes de controle biológico serão capazes de manter a população das comunidades de fitófagos em níveis aceitáveis. Por outro lado, o uso maciço de agentes de controle biológico também pode desequilibrar toda uma rede de relações complementares, impondo ao agroecossistema efeito semelhante aos de inseticidas sintéticos, o que não inclui, entretanto, contaminação do solo, água, alimento e dos organismos associados. Meadows (1993) considerou que, para se estimar o risco da liberação de qualquer agente microbiano de controle no ambiente, é importante conhecer a forma como ele interage com o meio ao seu redor, incluindo outros organismos presentes.

No Brasil, dois agentes efetivos de controle biológico da lagarta-do-cartucho são o Vírus da Poliedrose Nuclear de $S$. frugiperda (VPN - Sf) e o parasitóide Campoletis flavicincta (Ashmead) (Hymenoptera: Ichneumonidae). Tipos selvagens de baculovírus têm sido freqüentemente utilizados como bioinseticidas e atualmente são empregados em várias partes do mundo (Moscardi, 1999). Uma cepa de VPN - S f identificada e purificada no Brasil (Valicente et al., 1989) é considerada como tendo grande potencial para controlar esse inseto fitófago. C. flavicincta também tem se mostrado promissor como agente de controle biológico da lagarta-do-cartucho (Cruz et al., 1997b, Patel \& Habib, 1986). É um himenóptero de grande ocorrência (53\%) em campos de milho em Sete Lagoas, MG, seguida por Chelonus insularis (Cresson) (Hymenoptera: Braconidae) $(31,3 \%)$ e Eiphosoma spp. (Hymenoptera: Ichneumonidae) (15,6\%) (Cruz et al., 1997b).

Fêmeas de $C$. flavicincta, por meio do seu ovipositor, depositam seus ovos no interior das lagartas, obtendo maior sucesso em lagartas menores (Cruz et al., 1997b). Durante o desenvolvimento larval do parasitóide, os tecidos internos da lagarta servem de alimento para o hospedeiro, que ao atingir o final do último ínstar, rom- 
pe a cutícula da lagarta e em seguida tece seu casulo, onde ocorre a metamorfose que gerará invariavelmente um adulto da vespa. Quando da oviposição, existe a possibilidade das fêmeas deparem-se com hospedeiros já infectados pelo VPN - Sf. Esse mesmo vírus, após ser ingerido, encontra o $\mathrm{pH}$ alcalino do trato digestivo das lagartas, que rompe o corpo de inclusão protéico do vírus e permite a liberação do material genético do patógeno, que a partir de então, utiliza as células hospedeiras para sua multiplicação (Miltenburger \& Krieg, 1984). Sua virulência para um determinado hospedeiro é diretamente proporcional ao número de poliedros ingeridos e inversamente proporcional ao tamanho da lagarta. A maior eficiência de ambos agentes em lagartas em estádios iniciais de desenvolvimento caracteriza a possibilidade de competição pelos recursos (energia) de um mesmo hospedeiro. A liberação maciça de qualquer dos dois agentes no início do ciclo da cultura do milho reduz o dano à lavoura, mas pode também reduzir a disponibilidade de hospedeiros para ambos.

Liberações periódicas de vírus entomopatogênicos podem indiretamente, causar danos a organismos não-alvo como parasitóides e predadores, por deslocamento de competição ou por redução do recurso comum, que é o inseto hospedeiro (Capalbo \& De Nardo, 2000). A utilização do Vírus da Poliedrose Nuclear e do Vírus da Granulose para o controle de lepidópteros é considerada seletiva, pois aparentemente os vírus não se reproduzem nos tecidos de himenópteros (Beegle \& Oatman, 1975 e Irabagon \& Brooks, 1974). No entanto, podem afetar os parasitóides indiretamente pela produção de substâncias tóxicas para as suas larvas, pela redução do número de hospedeiros disponíveis ou pela morte dos hospedeiros antes do parasitóide haver completado seu desenvolvimento (Levin et al., 1981). A presença maciça de parasitóides pode também, diminuir o potencial de inóculo do vírus pela redução do volume de propágulos virais, conforme Powell (1985).

O presente estudo surgiu da necessidade de compreender algumas interações dos ciclos biológicos de VPN - Sf e de C. flavicincta, dependentes de lagartas de $S$. frugiperda em fase inicial de crescimento. Compreender algumas dessas interações pode ampliar a capacidade de utilização dessas duas espécies de organismos, contribuindo para a valorização da biodiversidade natural no processo produtivo do milho.

\section{Material e Métodos}

Os experimentos foram conduzidos no Laboratório de Criação de Insetos da Embrapa Milho e Sorgo, em Sete Lagoas, MG, em sala climatizada (temperatura de $25 \pm 2{ }^{\circ} \mathrm{C}$, UR de $70 \pm 10 \%$ e 12 horas de luz). As lagartas e os parasitóides utilizados nos experimentos provieram das criações mantidas em laboratório. Foi utilizada a cepa do vírus de nome "Sertaneja", que faz parte do banco de VPN - $S f$.

As lagartas, quando expostas ao vírus, tinham idade entre três e cinco dias (segundo e terceiro ínstares), considerada a melhor fase para a produção do parasitóide (Cruz et al., 1997a). A infecção com o VPN - Sf ocorreu quando as lagartas permaneceram por $24 \mathrm{~h}$ alimentando-se de discos de folhas de milho $(2,5 \mathrm{~cm}$ de diâmetro), umedecidas com o vírus, na concentração de $6 \times 10^{6}$ poliedros $/ \mathrm{ml}$. Foram feitas diluições a partir de um material purificado, de concentração inicial conhecida, caracterizadas em câmara de Newbauer. Lagartas que não tiveram contato com o vírus também se alimentaram com discos de folha de milho por $24 \mathrm{~h}$.

Após a emergência, os parasitóides adultos foram mantidos em lotes de cinco casais até 
o momento do parasitismo, quando estavam com cinco dias de idade, sem qualquer contato prévio com lagartas.

\section{A. Teste de confinamento com fêmeas} de $C$. flavicincta sem possibilidade de escolha (lagartas sadias ou infectadas pelo VPN - $S f$ )

Após alimentadas com folhas de milho infectadas ou não, 50 lagartas sadias ou 50 infectadas pelo VPN - $S f$ foram colocadas em frascos de vidro de boca larga, de 2,5 L, onde permaneceram em contato com três fêmeas de C. flavicincta por uma hora. Foram utilizadas cinco repetições. Findo o período de exposição aos parasitóides, as lagartas foram individualizadas em copos de plásticos, de $50 \mathrm{~mL}$ e alimentadas com dieta artificial à base de feijão e germe de trigo, conforme metodologia descrita por Cruz (2000). Trinta minutos após o término do período de parasitismo, dez lagartas de cada tratamento foram mortas e conservadas em álcool 70\%. A partir de então, a cada intervalo de oito horas, novas amostras de dez lagartas foram retiradas e processadas como anteriormente. A contagem do número de ovos e larvas do parasitóide foi feita pela dessecação de todas as lagartas amostradas e observação com o auxílio de um microscópio estereoscópico (10 x).

\section{B. Teste de livre escolha com fêmeas} de $C$. flavicincta em lagartas infectadas pelo VPN - $S f$ ou sadias

Dez lagartas de $S$. frugiperda infectadas pelo VPN - S $f$ (conforme detalhado anteriormente) e dez lagartas sadias foram colocadas juntas, em um mesmo frasco de 2,5 L, com uma fêmea de $C$. flavicincta, por uma hora. As lagartas tinham três dias e as fêmeas, cinco dias. O procedimento foi repetido por dez vezes. Após o parasitismo, as lagartas foram individualizadas em copo de plástico de $50 \mathrm{ml}$ e alimentadas com dieta artificial à base de feijão e germe de trigo. Quatro dias após o parasitismo, todas as lagartas foram mortas em álcool 70\%. Cada lagarta foi então, medida e, em seguida, dissecada, para a contagem dos ovos e larvas do parasitóide. Foi feita a determinação da presença ou não do VPN - S $f$ em cada lagarta. O diagnóstico da infecção causada pelo vírus foi baseado em sintomas típicos de infecção de $S$. frugiperda pelo VPN - $S f$ (aparência rósea no início e mais escurecida com o passar do tempo). Do mesmo modo como observou Cruz (2000), as lagartas infectadas têm a mobilidade reduzida e, por fim, tornam-se escuras, devido à desintegração do tecido interno, que se rompe ao menor contato, quando ocorre o extravasamento do conteúdo corporal. No caso de alguma dúvida quanto à presença ou não de poliedros do VPN - Sf nas lagartas, o diagnóstico foi feito em microscópio ótico (80x).

\section{Preferência de fêmeas de $C$. flavi- cincta por diferentes fontes de odores}

Para determinar se fêmeas do parasitóide são capazes de distinguir lagartas sadias de infectadas por meio de odores, no processo parasitário, foi utilizado um olfatômetro com possibilidade de múltipla escolha. Em um tubo de PVC (policloreto de vinila) de $20 \mathrm{~cm}$ de diâmetro e $20 \mathrm{~cm}$ de altura, foram feitas quatro perfurações eqüidistantes, de cinco cm cada (Figura 1).

$\mathrm{O}$ fundo do tubo foi vedado com filme plástico e a parte superior, com tecido organza. Em cada uma das quatro perfurações foi colocado um copo de plástico de $50 \mathrm{ml}$ de capacidade, com o seu fundo voltado para dentro do tubo de PVC. No fundo de cada copo, foi aberto um orifício de um $\mathrm{cm}$ de diâmetro, para dar acesso à parte interna do tubo de PVC. As arestas que resultaram da abertura desse orifício foram direci- 
onadas para o lado de dentro do copo, de forma que não oferecesse resistência à entrada das fêmeas no copo que continha as fontes de odor. Por outro lado, essas mesmas arestas dificultaram o retorno das fêmeas para o tubo de PVC.

As fontes de odor (1- apenas folha de milho; 2 - folha e uma lagarta sadia; 3 - folha e uma lagarta infectada) foram colocadas dentro de cada copo, que teve sua boca fechada por tecido de organza. A testemunha (4) foi representada por um copo vazio, também fechado pelo tecido de organza. A permeabilidade desse tecido é essencial para que se dê a formação do fluxo de ar, que irá conduzir os compostos voláteis até a câmara principal, após atravessar os copos com as fontes de odor.

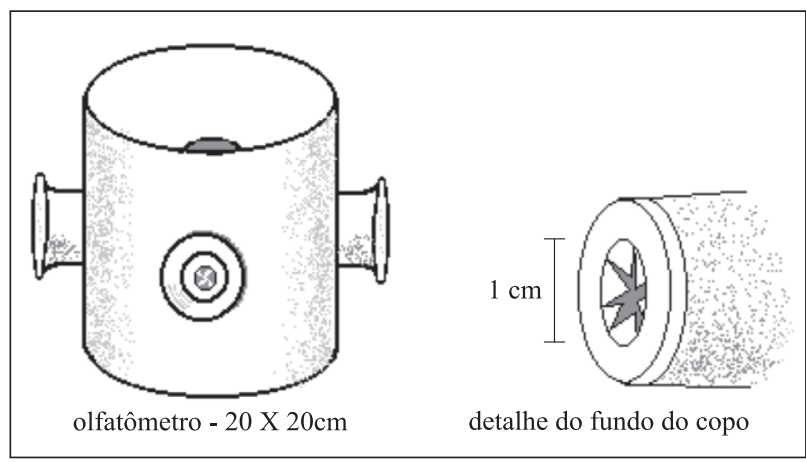

FIGURA 1. Olfatômetro de múltipla escolha utilizado para avaliar a capacidade de as fêmeas de $C$. flavicincta distinguirem lagartas de $S$. frugiperda sadias de lagartas infectadas pelo VPN - Sf. Desenho do primeiro autor.

Foram utilizadas cinco repetições e em cada uma delas foram liberadas sete fêmeas do parasitóide, número esse condicionado à disponibilidade de fêmeas na criação. A cada 60 minutos foi feita a contagem do número de fêmeas dentro dos copos que continham as diferentes fontes de odores ou nenhuma.
As fêmeas do parasitóide, após contato prévio de cinco dias com os machos, não ovipositaram até o momento do experimento. As lagartas ofertadas tinham entre cinco e seis dias de idade. Um dia antes dos testes, as lagartas infectadas alimentaram-se de folhas de milho umedecidas com o VPN - Sf (6 x $10^{6}$ poliedros $\left./ \mathrm{ml}\right)$, enquanto que as lagartas sadias alimentaram-se das folhas de milho sem o vírus. Como se utilizaram as mesmas fêmeas em observações feitas em dois dias consecutivos, foi oferecido mel puro, pincelado nas paredes internas do tubo de PVC e água, borrifada sobre o tecido que vedava o olfatômetro. Lagartas e as folhas foram substituídas no segundo dia de avaliação.

Análise estatística - Foi feita análise de variância nos experimentos 1 e 2 , e teste de $X^{2}$ no experimento 3, para detecção de diferenças estatísticas entre os tratamentos. O elevado número de valores nulos exigiu que, nos dois primeiros experimentos, os dados fossem transformados em $\mathrm{Vx}+0,5$.

\section{Resultados e Discussão}

A. Teste de confinamento com fêmeas de C. flavicincta sem possibilidade de escolha (lagartas sadias ou infectadas pelo VPN - Sf)

A1. Número de ovos por lagarta - O canibalismo ocorrido durante o período de parasitismo, comum durante o estádio larval dessa espécie de lepidóptero, reduziu o número de lagartas dissecadas de 250 para 230 nos dois tratamentos (Tabela 1). Independente de estarem ou não infectadas, 75,7 \% das lagartas dissecadas continham mais de um ovo. Fletcher et al. (1994) afirmaram que o superparasitismo (oviposição em um hospedeiro já parasitado) já foi considerado como sendo um "engano", mas atualmente é acei- 
to como sendo parte do comportamento adaptativo das fêmeas. Esses autores diferenciaram os fatores que influenciam o superparasitismo, que foram descritos em duas categorias: (1) variáveis externas, incluindo disponibilidade de hospedeiros, risco de mortalidade e densidade local de conspecíficos; (2) variáveis internas, incluindo o número de ovos que a fêmea dispõe para ovipositar e sua expectativa de vida.

A Figura 2 apresenta uma lagarta-do-cartucho morta pelo VPN - S $f$, tendo, no detalhe, ovo do parasitóide $C$. flavicincta. Nos experimentos de laboratório, as arenas são freqüentemente pequenas e completamente fechadas, prevenindo a migração do parasitóide e forçando-o a ovipositar no local (Lenteren \& Baker, 1978). Stiling (1987) considera que parasitóides com amplo suprimento de ovos sofreram um processo de seleção tal que as fêmeas depositam ovos em quase todos os hospedeiros que elas encontram, incluindo hospedeiros em que a probabilidade de sobrevivência de sua larva seja pequena.

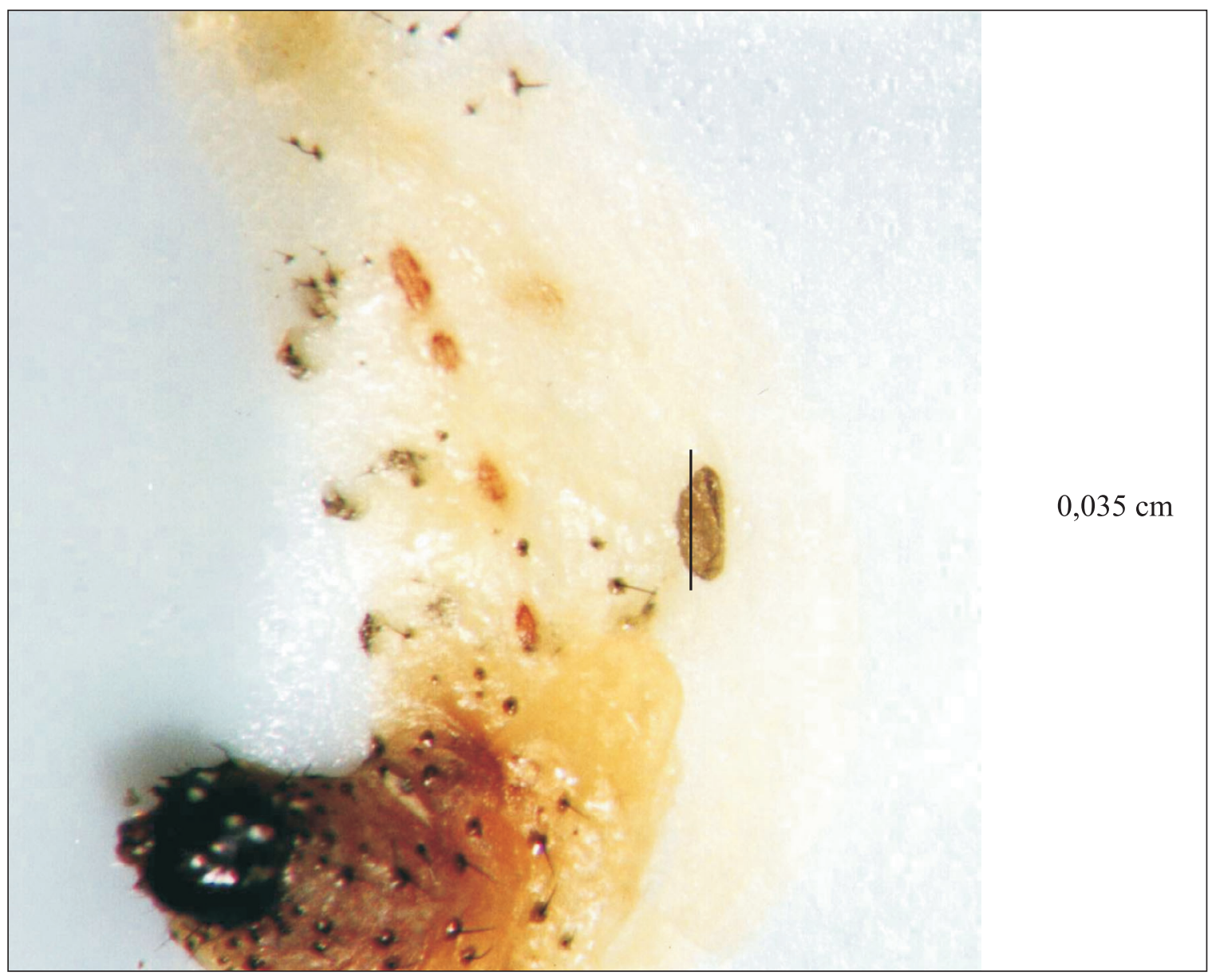

FIGURA 2. Lagarta de Spodoptera frugiperda com quatro dias de idade, morta pelo VPN - Sf, apresentando, no detalhe, ovo do parasitóide Campoletis flavicincta. (Fotografia: Dra. Maria de L. C. Figueiredo) 
Godfray (1994) reconhece que, em experimentos de laboratório, parasitóides confinados com seus hospedeiros recorram ao superparasitismo depois que todos os hospedeiros não parasitados já tiverem recebido pelo menos um ovo. Price (1974) relatou que parasitóides de larvas de estádios iniciais de desenvolvimento têm muito mais ovaríolos do que aqueles que parasitam os últimos estádios larvais. A alta capacidade reprodutiva é uma estratégia necessária para superar a alta taxa de mortalidade que ocorre nas progênies de espécies que parasitam ínstares iniciais dos hospedeiros, causada por doenças e predação do hospedeiro (Sandlan, 1979).

A proximidade entre as três fêmeas de $C$. flavicincta presentes em cada gaiola pode ter estimulado uma maior oviposição, independentemente da ocorrência prévia de ovos nos hospedeiros.

A2. Efeito do VPN - $S f$ sobre o n. $^{\circ}$ de ovos depositados - Foi encontrado um total de 752 ovos nas lagartas sadias e 523 nas infectadas, o que gerou um valor médio de ovos/lagarta igual a 3,365 (erro padrão da média $=0,13$ ) e 2,274 (epm =0,09), respectivamente. Feita a análise de variância, houve diferença estatística ao nível de $5 \%$ de probabilidade, com um coeficiente de variação de $25,5 \%$, o que indica preferência do parasitóide por lagartas sadias.

Para Versol \& Yendol (1982), é possível que os parasitóides evitem hospedeiros infectados com microrganismos, como faz Apanteles melanoscelus (Hymenoptera: Braconidae), que prefere lagartas sadias, fazendo pouco esforço para parasitar indivíduos infectados pelo vírus da poliedrose nuclear de Lymantria dispar L. (Lepidoptera: Lymantriidae). A possibilidade de discriminar um hospedeiro sadio de um hospedeiro infectado pode ser um ponto positivo para o uso dos VPN - Sf e do parasitóide em um programa de manejo integrado. A probabilidade de essa discriminação ocorrer no campo é grande, já que vírus e parasitóide participam de um processo evolutivo em que ocorrem interações que podem ser negativas para ambos (Hochberg, 1991).

Na Tabela 1, observa-se a frequiência de ocorrência de ovos do parasitóide nas lagartas sadias e infectadas, com os valores extremos apresentando as menores freqüências. Para Visser (1993), um parasitóide procurando por um hospedeiro num local onde também se encontram outros da mesma espécie pode inicialmente evitar aqueles previamente parasitados, para concentrar seus esforços na localização de hospedeiros não parasitados antes de seus competidores. Mais tarde, quando faltarem hospedeiros não parasitados, pode ser favorável gastar tempo e recurso adicionando ovos em um hospedeiro já parasitado.

\section{A3. Localização dos ovos e larvas do}

parasitóide - Independentemente do tratamento, foi possível observar, na primeira amostra de lagartas dissecadas (30 minutos após o parasitismo), que os ovos do parasitóide posicionavamse na extremidade anterior (14 ovos), parte mediana ( 12 ovos) e extremidade posterior (30 ovos) das lagartas. Nas dissecações posteriores a esse período, poucos foram os ovos encontrados em outros locais que não na extremidade posterior das lagartas. Isso sugere que, entre o parasitismo e a morte da primeira amostra de lagartas, não houve tempo suficiente para que os ovos fossem deslocados para a porção terminal. Esse deslocamento passivo dos ovos deve-se provavelmente aos movimentos do aparelho digestivo das lagartas, que conduzem o alimento para a extremidade posterior. A presença de ovos em diferentes posições dentro da lagarta indica que $C$. flavicincta não escolhe um local específico do hospe- 
TABELA 1. Frequiência de ovos de Campoletis flavicincta em lagartas de Spodoptera frugiperda sadias ou infectadas pelo VPN - S $f$ em teste de confinamento.

\begin{tabular}{ccc}
\hline $\begin{array}{c}\text { Classe de freqüência } \\
\left(\mathbf{n}^{\mathbf{0}} \text { ovos/lagarta) }\right.\end{array}$ & $\begin{array}{c}\text { Lagartas sadias } \\
(\mathbf{n}=\mathbf{2 3 0})\end{array}$ & $\begin{array}{c}\text { Lagartas infectadas } \\
(\mathbf{n}=\mathbf{2 3 0})\end{array}$ \\
\hline & $\mathbf{\%}$ & $\mathbf{\%}$ \\
\hline 0 & 2,61 & 1,74 \\
2 & 16,09 & 28,26 \\
3 & 23,48 & 33,91 \\
4 & 16,96 & 23,48 \\
5 & 15,22 & 6,52 \\
6 & 13,91 & 3,91 \\
7 & 5,22 & 1,3 \\
8 & 3,91 & 0 \\
9 & 0,87 & 0,44 \\
10 & 1,3 & 0,44 \\
11 & 0 & 0 \\
12 & 0 & 0 \\
Total & 0,43 & 0 \\
\hline
\end{tabular}

deiro para depositar seus ovos. Certamente, as fêmeas encontraram maior facilidade de ovipositar na parte posterior das lagartas, que ficam impossibilitadas de defender-se, por não detectarem a aproximação do parasitóide. Na parte posterior das lagartas, foi encontrada a grande maioria das larvas do parasitóide, próximas da inserção dos túbulos de Malpighi.

A4. Período de incubação dos ovos e competição entre larvas do parasitóide - As primeiras larvas eclodidas do parasitóide foram encontradas na dissecação feita 48 h após o parasitismo. Um dia após a eclosão, já foi possível observar que apenas uma das larvas (exceto em uma das observações) crescera, enquanto o restante manteve o tamanho de larvas recém-eclodidas. Essa larva maior certamente resultaria num adulto do parasitóide, confirmando o que invariavelmente ocorre com a espécie, em que apenas um parasitóide emerge de cada lagarta parasita- da. Quando existe um grande número de larvas de endoparasitóides solitários em um hospedeiro, as alternativas para a eliminação das larvas concorrentes, conforme Salt (1961) e Vinson \& Iwantsch (1980), são: eliminação por ataque físico, supressão fisiológica via toxinas, anoxia ou por privação nutricional. O primeiro ínstar das larvas de muitos parasitóides solitários é equipado com uma cápsula cefálica rígida e mandíbulas relativamente grandes, que são usadas para atacar outras larvas da mesma ou de outras espécies e posteriormente são perdidas quando a larva muda para o segundo ínstar e inicia uma fase de rápido crescimento (Godfray, 1994). Vinson (1972) fornece evidências de que há competição e que ocorre ataque físico durante o primeiro instar entre larvas de $C$. sonorensis.

Na competição intra-específica, a eliminação das larvas concorrentes do parasitóide dentro de uma mesma lagarta deve dar-se por ataque 
físico, dada a morfologia das larvas de primeiro estádio de $C$. flavicincta (presença de cápsula cefálica rígida apenas em larvas de primeiro ínstar - Figura 3, mais nítidas nas larvas 1 e 2, e mandíbulas, que são pouco desenvolvidas nos ínstares posteriores), sugerindo que o embate entre as larvas competidoras deve ocorrer no primeiro estádio de desenvolvimento. Na Figura 3, é possível observar que apenas uma das larvas do parasitóide desenvolveu-se ( $\left.\mathrm{n}^{\circ} .1\right)$, enquanto as demais tinham as mesmas dimensões de larvas recém-eclodidas.

Em apenas uma das 460 lagartas dissecadas foram encontradas duas lagartas maiores que as demais (ao todo, cinco larvas do parasitóide na mesma lagarta), no $3^{\circ}$ dia após o parasitismo. As três larvas menores não cresceram além do tamanho que tinham ao eclodirem.

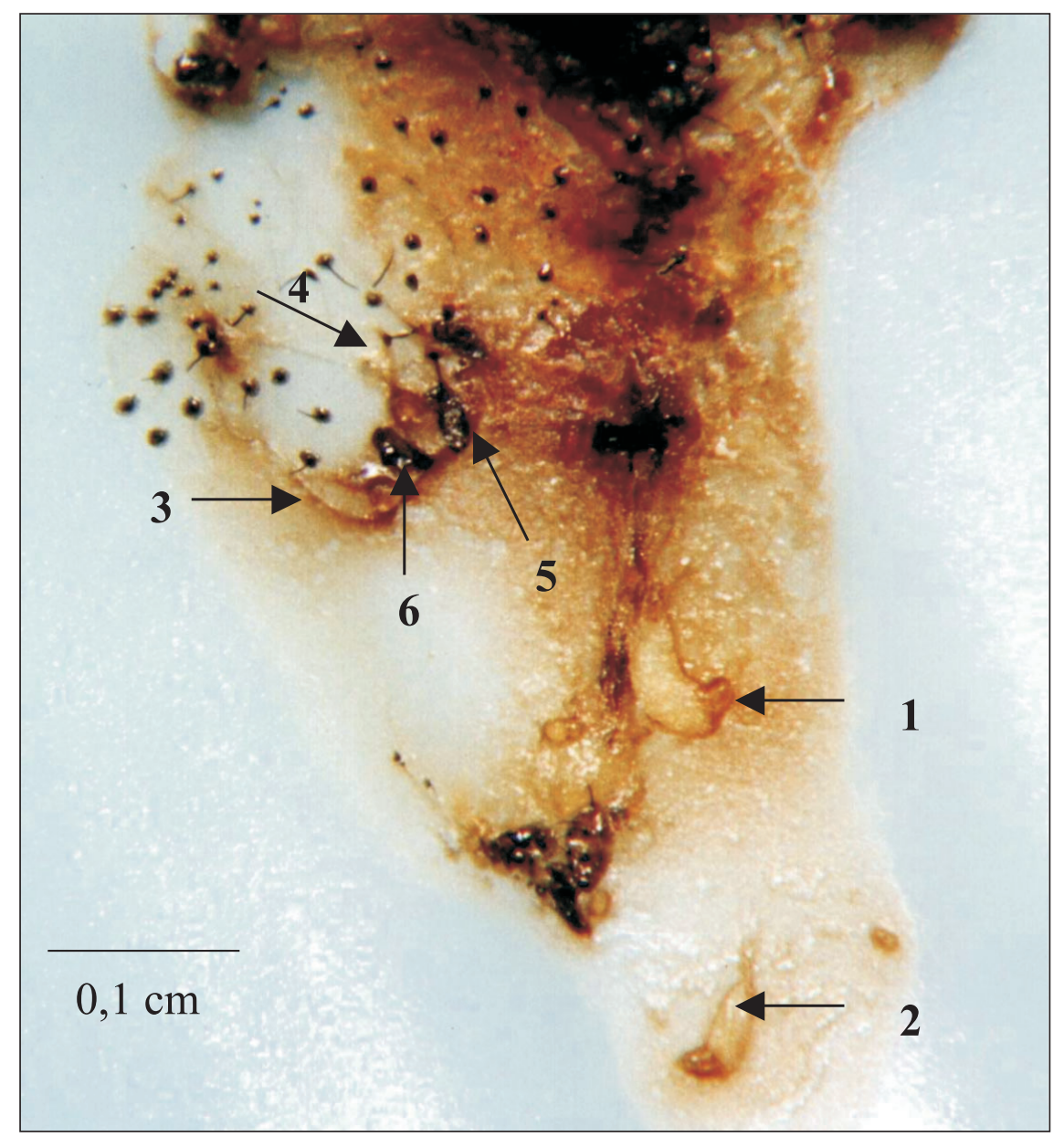

FIGURA 3. Lagarta do cartucho com sete dias, morta pelo vírus da poliedrose nuclear (VPN - Sf). As larvas do Campoletis flavicincta têm em torno de $24 \mathrm{~h}$ de eclosão. A larva maior ( $\mathrm{n}^{\circ}$. 1) tem 0,15 $\mathrm{cm}$, e as menores $\left(\mathrm{n}^{\circ} .2,3\right.$, e 4) $0,075 \mathrm{~cm}$, medida essa que inclui a expansão em forma de cauda, presente na porção terminal das larvas recém-eclodidas, que pode ser mais facilmente observada na larva de $n^{\circ} 2$. Pode-se notar, ainda, a presença de dois ovos ( $n^{\circ} 5$ e 6). (Fotografia: Dra. Maria de L. C. Figueiredo) 
Nessa lagarta, não deve ter havido o enfrentamento das duas larvas competidoras maiores até o momento da morte do hospedeiro no álcool 70\%. A observação de duas larvas grandes em uma mesma lagarta pode ser um indício que reduz a possibilidade da existência de supressão química na competição entre as larvas de $C$. flavicincta, já que um composto inibidor de crescimento deve agir igualmente sobre todas as larvas competidoras, exceto sobre a larva que primeiro eclodiu e liberou o composto, como ocorre com braconídeos da subfamília Aphidiinae, citado por Godfray (1994).

Quando da presença conjunta do VPN e de larvas de Campoletis sonorensis Cameron (Hymenoptera: Ichneumonidae), em lagartas de S. frugiperda em $2^{\circ}$ e $3^{\circ}$ estádios, o vírus foi um competidor superior e dominou os recursos do hospedeiro (Escribano et al., 2000a).

B. Teste de livre escolha com fêmeas de $C$. flavicincta em lagartas infectadas pelo VPN - $S f$ ou sadias

Parte da mortalidade das 100 lagartas inicialmente utilizadas deveu-se ao canibalismo natural existente entre as lagartas de $S$. frugiper$d a$. Foram contados 101 ovos nas 94 lagartas in- fectadas e 89 ovos nas 98 lagartas sadias. Independente do tratamento, em $85 \%$ das lagartas foram encontrados mais de um ovo (Tabela 2), confirmando o resultado obtido no primeiro ensaio, onde também ocorreu superparasitismo na maioria das lagartas. Há algumas circunstâncias em que um parasitóide solitário pode ser beneficiado pela colocação de mais ovos em um hospedeiro - pode saturar o sistema de defesa do hospedeiro ou aumentar a probabilidade de que um dos indivíduos da sua prole derrote uma possível larva de um parasitóide concorrente (Godfray, 1994). O número médio de ovos depositados por fêmea não foi significativamente diferente nos dois tratamentos. A saturação do ambiente da gaiola com os voláteis provenientes das lagartas pode ter impedido a discriminação por parte das fêmeas do parasitóide entre lagartas sadias e infectadas.

Os valores médios foram de 10,1 ovos / fêmea no tratamento com lagartas sadias e 8,9 ovos/fêmea nos tratamentos em lagartas infectadas. Esses valores foram inferiores aos obtidos no primeiro experimento: 25,1 ovos/fêmea em lagartas sadias e 17,4 em lagartas infectadas. No primeiro experimento, foram encontradas lagartas com até 12 ovos, enquanto que o número

TABELA 2. Frequiência de ovos de Campoletis flavicincta em lagartas de Spodoptera frugiperda sadias e infectadas pelo VPN - S $f$ em teste de livre escolha.

\begin{tabular}{ccc}
\hline $\begin{array}{c}\text { Classe de freqüência } \\
\left(\mathbf{n} .^{\mathbf{0}} \text { ovos / lagarta) }\right.\end{array}$ & $\begin{array}{c}\text { Lagartas sadias } \\
\mathbf{\%} \\
(\mathbf{n = 9 8 )}\end{array}$ & $\begin{array}{c}\text { Lagartas infectadas } \\
\mathbf{\%}\end{array}$ \\
\hline 0 & 4,08 & $\mathbf{( n = 9 4 )}$ \\
1 & 5,10 & 2,13 \\
2 & 8,16 & 9,57 \\
3 & 42,86 & 17,02 \\
4 & 39,80 & 36,17 \\
Total & 100 & 35,11 \\
\hline
\end{tabular}


máximo no segundo experimento foi de quatro ovos. A maior competição por hospedeiros no primeiro caso (três fêmeas /gaiola) pode ter sido o fator determinante dessa diferença, aumentando as chances de uma mesma lagarta ser parasitada mais vezes.

Fêmeas de parasitóides usam a freqüência de contatos com fêmeas da mesma espécie como um indicador de que há potenciais competidoras no ambiente (Godfray, 1994). O mesmo autor afirma que, teoricamente, parasitóides solitários nunca deveriam gerar superparasitismo, mas a quantidade de ovos num mesmo hospedeiro aumenta com o aumento do número de fêmeas à procura de hospedeiros.

Outro ponto relevante que deve ser considerado na diferença da amplitude do número de ovos depositados nos dois experimentos é a existência de marcação química que as fêmeas de parasitóides deixam após a oviposição. Uma fêmea só consegue identificar a marcação química feita por ela (Godfray, 1994), o que pode ter diminuído a possibilidade de uma mesma lagarta receber número maior de ovos, como observado no experimento 1. Na teoria, é vantajoso que a fêmea reconheça um hospedeiro já parasitado, pois uma larva secundária tem maiores chances de ser eliminada. Isso evita gasto de ovos e tempo em um local onde sua progênie terá poucas chances de sobreviver, reduzindo o risco de danificar o hospedeiro e colocar em risco sua própria progênie (Lenteren, 1981).

Uma fêmea pode evitar o superparasitismo se ela puder reconhecer que o seu hospedeiro já foi previamente parasitado, habilidade chamada de "discriminação de hospedeiro" (Godfray, 1994). Muitas espécies de parasitóides usam marcações químicas para distinguir hospedeiros parasitados de não parasitados e evitar o superparasitismo (Lewis \& Martin Jr. 1990).
Houve diferença significativa no tamanho médio das lagartas infectadas $(0,59 \pm 0,02$ $\mathrm{cm})$ quando comparadas com lagartas sadias $(0,68 \pm 0,01)$. Pode-se inferir que, passados quatro dias da infecção, quando as lagartas foram mortas, já houve efeito do VPN - Sf, que impôs uma redução na taxa de alimentação e, conseqüentemente, no tamanho das lagartas infectadas.

\section{Preferência de fêmeas de $C$. flavi- cincta por diferentes fontes de odores}

O trabalho com o olfatômetro mostrou que o tratamento com lagartas livres do VPN-Sf (1), atraiu $50 \%$ das fêmeas do parasitóide. Esse valor foi de $32,1 \%, 14,3 \%$ e $3,5 \%$, nos tratamentos com VPN - S $f(2)$, com folhas (3) e na testemunha (4), respectivamente. Pelo teste de $\mathrm{c}^{2}$, apenas não foi possível comprovar diferença ao nível de $10 \%$ de probabilidade entre os tratamentos 1 e 2 . O valor do $\mathrm{c}^{2}$ foi 14 , com $1 \%$ de significância e de 5,54 para os tratamentos com folhas, com $10 \%$ de significância. Portanto, não foi possível, pelo experimento desenvolvido, detectar a capacidade de fêmeas de $C$. flavicincta identificarem lagartas sadias de infectadas pelo VPN - S $f$.

A presença de um menor número de ovos de $C$. flavicincta em lagartas infectadas pelo VPN - S $f$ (primeiro experimento) demonstrou que as fêmeas do parasitóide foram menos estimuladas a depositar ovos em lagartas infectadas do que nas sadias. Entretanto, isso não provou que elas preferiram as lagartas sadias em resposta a um estímulo externo (cairomônio), gerando um menor número de visitas e, conseqüentemente, de ovos nas lagartas infectadas. Outro modo de explicar o menor número de ovos em lagartas infectadas seria a presença de algum fator interno que determinaria a qualidade do hospedeiro, que 
não afetaria o número de visitas. Somente após inserir o ovipositor no hospedeiro é que a fêmea seria capaz de perceber a condição da lagarta (se saudável ou infectada). Strand (1985) afirmou que muitos parasitóides utilizam-se de marcação externa ou de alguma forma de marcação interna para discriminar hospedeiros parasitados de hospedeiros não parasitados.

A eficiência do olfatômetro foi comprovada quando se observou apenas uma fêmea dentro do copo testemunha (4) (Tabela 3), enquanto que no tratamento com lagartas e folhas sem vírus (i) foram observadas 14 fêmeas. Desse modo, pode-se concluir que são realmente os sinais químicos indispensáveis na localização do hospedeiro. Pode-se afirmar, também, que o conjunto de substâncias exaladas pelas folhas, lagartas e fezes foi mais atraente para as fêmeas do que apenas os odores provenientes das folhas. Muitos dos fatores que levam o parasitóide até o hospedeiro são compostos químicos originados do hospedeiro (cairomônios) ou da planta que alimenta o hospedeiro (sinomônios) (Powell, 1985). Lagartas contaminadas comem menos, defecam menos e, portanto, têm menor atratividade para os parasitóides, quando comparadas com lagartas sadias. Esse seria um fator a mais a favorecer o uso conjunto dos dois agentes controladores.

Godfray (1994) afirmou que parasitóides localizam seus hospedeiros usando uma variedade de fatores químicos, táteis e visuais. A seleção natural atuou no hospedeiro minimizando, o quanto possível, os estímulos que pudessem ser usados pelo parasitóide na localização do hospedeiro. Por isso, não é surpreendente que a maioria dos atraentes e arrestantes químicos usados pelos parasitóides seja produzida quando o hospedeiro alimenta-se ou quando defeca, duas atividades que não podem ser evitadas. Segundo o mesmo autor, o que mais atraiu fêmeas de Cotesia marginiventris (Hymenoptera: Braconidae) foi, primeiramente, lagartas de Spodoptera exigua, seguidas de fezes das lagartas e, por fim, folhas danificadas pelas lagartas.

Folhas danificadas artificialmente atraem com menor intensidade. Se a saliva foi colocada em folhas danificadas artificialmente, as fêmeas do parasitóide responderam como se estivessem na presença de lagarta alimentando-se. Aparentemente, os compostos químicos da saliva das lagartas estimulam a planta a liberar terpenóides e indóis, que são atrativos para o parasitóide (Godfray, 1994). Fêmeas de C. sonorensis respondem ao odor de plantas de algodão, movimen-

TABELA 3. Número de fêmeas de Campoletis flavicincta atraídas por diferentes tratamentos, num olfatômetro de múltipla escolha, em dois dias de observação.

\begin{tabular}{ccccc}
\hline \multirow{2}{*}{ Gaiolas } & \multicolumn{4}{c}{ Tratamentos } \\
\cline { 2 - 5 } & $\begin{array}{c}\text { Lagartas } \\
\text { sem vírus }\end{array}$ & $\begin{array}{c}\text { Lagartas } \\
\text { com vírus }\end{array}$ & Só folhas & Testemunha \\
\hline 1 & 2 & 4 & 0 & 1 \\
2 & 3 & 1 & 2 & 0 \\
3 & 3 & 1 & 1 & 0 \\
4 & 2 & 2 & 1 & 0 \\
5 & 4 & 1 & 0 & 0 \\
\hline Total & 14 & 9 & 4 & 1 \\
\hline
\end{tabular}


tando as antenas sobre a planta e tocando repetidamente com seu ovipositor a superfície da mesma (Williams et al. 1988). A mesma espécie é atraída por alguns componentes voláteis presentes em flores e outras partes das plantas (Elzen et. al., 1983), que também atestaram que o dano provocado pelo ataque de herbívoros pode liberar grande quantidade de compostos envolvidos na atração dos parasitóides.

Os sintomas correspondentes à infecção do VPN - S $f$ (redução no tamanho e na agilidade das lagartas), quando presentes em indivíduos de uma mesma geração de lagartas, pode tornar justamente as lagartas infectadas mais susceptíveis ao parasitismo. Entretanto, o parasitismo em lagartas sadias seria favorecido, pois antes da oviposição é necessária a aproximação do parasitóide junto ao hospedeiro, que é estimulada pelos odores emanados do processo de mastigação e defecação.

Os agentes bióticos utilizados no controle biológico de fitófagos não estão isentos de causarem impacto negativo no equilíbrio das redes tróficas de um agroecossistema. Para Capalbo \& de Nardo, (2000), a adoção de um Agente Microbiano de Controle (AMC) implica a possibilidade de sua ampla distribuição ambiental e, consequentemente, a exposição de outros organismos não-alvo, além da própria praga que se deseja controlar. As mesmas autoras afirmam que, mesmo que o AMC seja de ocorrência natural na região de utilização do produto, ele possivelmente estará disponível durante a aplicação de forma numérica, espacial e temporal diferente da usual, surgindo daí a necessidade de uma avaliação de risco do uso desses agentes. Parasitóides e vírus competem pelos recursos quando presentes no mesmo hospedeiro, e isso freqüentemente, é altamente negativo tanto para o vírus como para o parasitóide (Escribano et al., 2000b).
Lasalle \& Gauld (1991) qualificam os himenópteros parasitóides como essenciais na preservação do equilíbrio ecológico e na manutenção da diversidade nos ecossistemas terrestres. O controle biológico de pragas é um dos importantes segmentos precursores da mudança de paradigmas na pesquisa agrícola, e sucede o período do uso indiscriminado de agrotóxicos por parte dos produtores rurais. É bastante promissora a utilização de agentes biológicos na redução do prejuízo provocado por insetos fitófagos e, nesse aspecto, o Brasil tem especial relevância no quadro mundial, não só pela qualidade de sua pesquisa agropecuária e biológica, mas também por sua imensa biodiversidade, potencialmente rica em agentes de controle populacional.

A aplicação precoce e contínua de VPN em uma dada lavoura pode reduzir as fontes de odores, oriundas da saliva e das fezes das lagartas e, por conseguinte, reduz a atratividade da área para a população de parasitóides responsáveis pelas futuras gerações presentes na área em questão. Ao mesmo tempo, a preferência das fêmeas do parasitóide por hospedeiros sadios é um elemento que pode minimizar o impacto negativo do vírus sobre a população do parasitóide. A utilização dos dois agentes controladores numa mesma área deve respeitar critérios predeterminados, baseados em conhecimentos mais aprofundados da ecologia dos organismos envolvidos.

\section{Agradecimentos}

À Embrapa Milho e Sorgo, à Universidade Federal de São Carlos e aos órgãos de fomento à pesquisa, CNPq e CAPES.

\section{Literatura Citada}

ALPHEN, J. J. M. van; VET, E. M. An evolutionary approach to host finding and selection. In: WAAGE, J.; GREATHEAD, D. 
(Ed.). Insect parasitoids. London, Academic Press, 1985. p. 23-61.

BEEGLE, C.C.; OATMAN, E.R.. Effect of a polyhedrosis virus on the relationship between Trichoplusia ni (Lepidoptera: Noctuidae) and the parasite Hyposoter exigua (Hymenoptera: Ichneumonidae). Journal of Invertebrate Pathology, v. 25, p. 59-71, 1975.

CAPALBO, D.M.F.; DE NARDO, E. A B. Análise de risco e impacto ambiental do uso de agentes de controle biológico. p. 351-387. In MELO, I.S.; AZEVEDO, J. L. (Eds.) Controle Biológico, 2. Jaguariúna, Embrapa, 2000. 387p.

CRUZ, I. A lagarta-do-cartucho na cultura do milho. Sete Lagoas: Embrapa - CNPMS. 1995.45p. (Embrapa - CNPMS, Circular Técnica, 21).

CRUZ, I.; FIGUEIREDO, M. L. C.; VALICENTE, F. H.; OLIVEIRA, A. C. Application rate trials with a Nuclear Polyhedrosis Virus to control Spodoptera frugiperda on maize. Anais da Sociedade Entomológica do Brasil, v. 6, p. 145-152, 1997a.

CRUZ, I.; FIGUEIREDO, M.L.C.; OLIVEIRA, A. C.; VASCONCELOS, C. A. Damage of Spodoptera frugiperda (Smith) in different maize genotypes cultivated in soil under three levels of aluminium saturation. International Journal of Pest Management, v.45, p. 293-296, 1999.

CRUZ, I., M.L. C. FIGUEIREDO, E. P. GONÇALVES, D.A.N. LIMA \& E. E. DINIZ. Efeito da idade de lagartas de Spodoptera frugiperda (Smith) (Lepidoptera: Noctuidae) no desempe- nho do parasitóide Campoletis flavicincta (Ashmead) (Hymenoptera: Ichneumonidae) e consumo foliar por lagartas parasitadas e nãoparasitadas. Anais da Sociedade Entomológica do Brasil, v. 26, p. 229-234. 1997.b.

CRUZ, I.; TURPIN, F.T. Yield impact of larval infestation of the fall armyworm Spodoptera frugiperda (J.E. Smith) to mid-whorl growth stage of corn. Journal of Economic Entomology, v. 76, p. 1052-1054. 1983.

CRUZ, I. Utilização do Baculovirus no controle da lagarta-do-cartucho do milho, Spodoptera frugiperda. In MELO, I.S.; AZEVEDO, J.L. (Eds.), Controle Biológico, 3. Jaguariúna, Embrapa, 2000. 308p.

ELZEN, G.W., WILLIAMS, H.J.; VINSON, S.B.. Response by the parasitoid Campoletis sonorensis (Hymenoptera: Ichneumonidae) to chemicals (Synomones) in plants: implications for host location. Environmental Entomology v. 12 , p. $1873-1877.1983$.

ESCRIBANO, A., WILLIAMS, T.; GOULSON, D.; CAVE, R. D.; CHAPMAN, J. W.; CABALLERO, P. Effect of parasitism on a nucleopolyhedrovirus amplified in Spodoptera frugiperda larvae by Campoletis sonorensis. Entomologia Experimentalis et Applicata v.97, p. 257-264. 2000a.

ESCRIBANO, A.; WILLIAMS, T.; GOULSON, D.; CAVE, R. D.; CABALLERO, P. Parasitoidpathogen-pest interactions of Chelonus insularis, Campoletis sonorensis, and a nucleopopyhedrovirus in Spodoptera frugiperda larvae. Biological Control, v. 19, p. 256-273. $2000 b$. 
FLETCHER, J.P.; HUGHES, J. P.; HARVEY, I. F. Life expectancy and egg load affect oviposition decision of a solitary parasitoid. Proceedings of the Royal Society of London, v. 258, p.163-167. 1994.

GODFRAY, H.C.J. Parasitoids: behavioral and evolutionary ecology. $1^{\text {st }}$. ed., New Jersey, Princeton University Press, 1994. 437p.

HOCHBERG, M.E. Intra-host interactions between a braconid endoparasitoid, Apanteles glomeratus, and a baculovirus for larvae of Pieris brassicae. Journal of Animal Ecology, v. 60, p. 51-63. 1991.

IRABAGON, T. A.; BROOKS, W.M. Interaction of Campoletis sonorensis and Nuclear polyhedrosis virus in larvae of Heliothis virescens. Journal of Economic Entomology, v. 67, p. 229-231, 1974.

FIGUEIREDO, M.L.C.; MARTINS-DIAS, A.M.P.;CRUZ,I. Relação entre a lagarta-do-cartucho e seus agentes de controle biológico natural na produção de milho. Pesquisa Agropecuária Brasileira, v.41, n.12, p.16931698, 2006

LA SALLE, J.; GAULD, I.D. Parasitic Hymenoptera and the biodiversity crisis. REDIA. v 54, p. 315-334. 1991.

LENTEREN, J.C. van; BAKER, K. Behavioral aspects of the functional responses of a parasite (Pseudeucoila bochei Weld) to its host (Drosophila melanogaster). Netherlands Journal of Zoology. Leiden, v. 28, p. 3213-233, 1978.

LENTEREN, J. C. van Host discrimination by parasitoids. In NORDLUND, D. A.; JONES R.L.;
LEWIS, W.J. (Ed.). Semiochemicals. New York: J. Wiley, 1981. p. 153-180.

LEVIN, D.B.; LAING, J.E.; JACQUES, R.P. Interactions between Apanteles glomeratus (L.) (Hymenoptera: Braconidae) and granulosis virus in Pieris rapae (L.) (Lepidoptera: Pieridae). Environmental Entomology, v. 10. p. 656-68. 1981.

LEWIS, W.J.; MARTIN JR, W.R. Semiochemicals for use with parasitoids: status and future. Journal of Chemical Ecology, v. 16, p. 3067-3089. 1990.

MEADOWS, M.P. Bacillus thuringiensis in the environment - ecology and risk assessment, In: ENTWISTLE, P.F.; CORY, J.S.; BAILEY, M.J.; HIGGS, S. (Eds.). Bacillus thuringiensis: an environmental biopesticide - theory and practice. Chichester: John Wiley. p.1. 93-200. 1993.

MILTENBURGER, H.G.; KRIEG, A.. Bioinsecticides: II. Baculoviridae. In LISS, A. (Ed.). Advances in Biotechnological Process 3. New York. p. 291-31. 1984.

MOSCARDI, F. Assessment of the application of baculoviruses for control of Lepidoptera. Annual Review Entomology, v. 44, p. 257-289. 1999.

PATEL, P.N. \& M.E.M. HABIB. Levantamento e eficiência de insetos parasitos de Spodoptera frugiperda. Revista de Agricultura, v. 6, p. 93100. 1986.

POWELL, W. Enhancing parasitoids activity in crops. In: WAAGE, J.; GREATHEAD, D. (Ed.). 
Insect parasitoid. London: Academic Press, 1985. p. 319-335.

PRICE, P.W. Strategies for egg production. Evolution, v. 28, p. 76-84. 1974.

SALT, G. Competition among insect parasitoids. In "Mechanismis Biological Competition". Symposium of the Society of Experimental Biology 15, Cambridge, University Press. v. 5, p. 81-95. 1961.

SANDLAN, K. Sex ratio regulation in Coccygomimus turonella Linnaeus (Hymenoptera: Ichneumonidae) and its ecological implications. Ecological Entomology, v. 4, p. 365-378. 1979.

STILING, P.D. The frequency of density dependence in insect host-parasitoid systems. Ecology, v. 8, p. 844-856. 1987.

STRAND, M. R. The physiological interactions of parasitoids with their hosts and their influence on reproductive strategies. In: WAAGE, J.; GREATHEAD, D. (Ed.). Insect parasitoid. London: Academic Press, 1985. p. 97-129

VALICENTE, F. H.; PEIXOTO, M.J.V.V.D.; PAIVA, E.; KITAJIMA, E. Identificação e purificação de um vírus de poliedrose nuclear da la- garta do cartucho, Spodoptera frugiperda. Anais da Sociedade Entomológica do Brasil, v. 18, p. 71-82. 1989.

VERSOL, P.L.; YENDOL, W. G.. Discrimination by the parasite, Apanteles melanoscelus, between healthy and virus-infected moth larvae. Environmental Entomology, v. 11, p. 42-45. 1982.

VINSON, S.B. Competition and host discrimination between two species of tobacco budworm parasitoids. Annals of the Entomological Society of America, v. 5, p. 229236. 1972.

VINSON, S.B.; IWANTSCH, G.F. Host regulation by insect parasitoids. Quarterly Review of Biology, v. 55, p. 143-165. 1980.

VISSER, M.E. Adaptative self- and conspecific parasitism in the solitary parasitoid Leptopilina heterotoma. Behavioral Ecology, v.4, p. 22-28. 1993.

WILLIAMS, H.J.; ELZEN, G.W.; VINSON, S.B. Parasitoids-host-plant interactions, emphasizing cotton (Gossypium), p. 171-191. In: BARBOSA, P.; LETOURNEAU, D. K. (Eds.), Novel aspects of insect-plant interactions. New York, Wiley, 1988. 362 p. 